\title{
Diagnostic accuracy of an intrathecal test dose in epidural analgesia
}

The authors evaluated the accuracy of an intrathecal test dose (TD) to rule out unintentional subarachnoid injection in a prospective and double-blind study. Twenty-nine unmedicated patients scheduled to receive continuous spinal analgesia for their surgical procedures entered the study. After placement of noninvasive monitoring ( $E C G, B P$ and $\mathrm{SpO}_{2}$ ), an intrathecal catheter was placed in the lumbar area. In the supine position 15 patients in the study group received lidocaine $45 \mathrm{mg}+$ epinephrine $15 \mathrm{mg}$ and 14 patients in the control group received normal saline $3 \mathrm{ml}$ intrathecally. After the injection, a blinded observer assessed the presence of the following signs at one minute intervals for five minutes: sensory loss by pin-prick $(P)$ over the lumbar and sacral dermatomes, ability to raise legs $(R)$, and subjective feeling of warmth $(W)$ and heaviness $(H)$ over the lower limbs. For each sign the sensitivity (SN), specificity (SP), and negative (-) and positive $(+)$ predictive value $(P V)$ were calculated. At four minutes $S N$ reached $100 \%(C I$ 78-100\%) for $R$ and $H$, while only $R$ obtained a SP of $93 \%$ (CI 66-100\%). Using $R$ as detector of intrathecal injection the $-P V$ was $100 \%$ and the $+P V 25 \%$ (assuming a $2 \%$ prevalence of unintentional spinal). We conclude that, with our test dose; (a) four minutes are needed to recognize signs of intrathecal injection; (b) leg-raising is a reliable sign; and (c) inquiring about other signs may only decrease the diagnostic accuracy of this test.

Grâce à une étude prospective et à double insu, les auteurs ont évalué la valeur de la dase-test intrathécale (DT) utilisée pour diagnostiquer linjection intrathécale accidentelle. Vingtneuf patients non prémédiqués programmés pour une intervention sous rachianesthésie continue sont inclus dans l'étude. Après la mise en place d'un monitorage non effractif (ECG, TA et $\mathrm{SpO}_{2}$ ), un cathéter intrathécal est inséré à la région lombaire. Couchés sur le dos, 15 patients de l'étude reçoivent de

\section{Key words}

ANAESTHETIC TECHNIQUES: epidural, lumbar, test dose, spinal.

From the Department of Anesthesiology, Hahnemann University Hospital, Broad and Vine Street, Philadelphia, PA 19102-1192.

Address correspondence to: Dr. Pietro Colonna-Romano. Accepted for publication Ist April, 1994.
Pietro Colonna-Romano MD, Ruby Padolina MD, Nagaraj Lingaraju MD, Leonard E. Braitman PhD la lidocaïne $45 \mathrm{mg}+$ épinéphrine $15 \mu \mathrm{g}$ et 14 patients du groupe contrôle reçoivent $3 \mathrm{ml}$ de soluté physiologique intrathécal. Après linjection, un observateur neutre recherche à des intervalles d'une minute pendant cinq minutes la présence des signes suivants: perte de sensibilité à la piqûre $(P)$ au niveau des dermatomes lombaires et sacrés, l'habileté de soulever les jambes $(R)$, et la sensation de chaleur $(H)$ aux membres inférieurs. Pour chacun des signes, la sensibilité (SN), la spécificité (SP) et les valeurs préditives (VP) négative $(-)$ et positive $(+)$ sont calculées. A la quatrième minute, la SN atteint 100\% (CI 78-100\%) pour $R$ et $H$, alors que seulement $R$ obtient une $S P$ de $93 \%$ (CI 66-100\%). En utilisant $R$ comme détecteur d'injection intrathécale, la -VP était de $100 \%$ et la $+V P 25 \%$ (en assumant une prévalence de $2 \%$ de rachianesthésie accidentelle). Nous concluons qu'avec notre dose-test (a) quatre minutes sont requises pour détecter les signes dinjection intrathécale; (b) la levée de la jambe est un signe fiable; et (c) les questions posées sur d'autres signes ne peuvent que diminuer la valeur diagnostique du test.

During the performance of a lumbar epidural block, the catheter may be unintentionally inserted into the subarachnoid space. To avoid intrathecal injection of local anaesthetic intended for epidural analgesia, CSF aspiration via the catheter is first attempted. While a positive aspiration is diagnostic of intrathecal cannulation, failure to aspirate does not rule it out. Therefore an intrathecal test dose (TD), containing a small amount of local anaesthetic is injected to identify subarachnoid cannulation. The signs of a positive intrathecal TD should be apparent in about three to four minutes. ${ }^{1}$

We designed this prospective and double-blinded study to assess: (a) the accuracy of an intrathecal TD in detecting signs of subarachnoid injection; (b) the minimal time needed to optimize the diagnostic accuracy of an intrathecal TD; and (c) the most reliable marker(s) of subarachnoid injection.

\section{Methods}

After institutional approval by the Human Research Committee, 29 unmedicated patients (age 60-81 yr) gave informed consent. They were free of neuromuscular disease and scheduled to undergo elective surgical ortho- 
paedic or vascular procedures of the lower limbs under continuous spinal analgesia. We established non-invasive monitoring (BP, ECG and $\mathrm{SpO}_{2}$ ) and infused 300-500 ml balanced salt solution iv. A 19-gauge catheter was placed intrathecally in the lumbar area at the $\mathrm{L}_{2}-\mathrm{L}_{3}$ or $\mathrm{L}_{3}-\mathrm{L}_{4}$ interspace via an 18-gauge Tuohy needle. Aspiration of CSF confirmed correct catheter position. $\mathrm{Pa}$ tients were then sequentially (alternately) assigned to the study (SG) or to the control group (CG). In the supine position, 15 patients in the SG received intrathecal lidocaine $45 \mathrm{mg}+$ adrenaline $15 \mathrm{mg}$ with no dextrose $(3 \mathrm{ml})$, while 14 patients in the $\mathrm{CG}$ received intrathecal saline $(3 \mathrm{ml})$. Baseline BP was established at the time of injection and measured every minute for five minutes. One minute after the injection, a blinded observer (an attending anaesthetist or an anaesthesia resident with more than six months in training) assessed the presence of the following signs every minute for five minutes: sensory loss by pin-prick (P) over the lumbar and sacral dermatomes (absence of sensation in any one dermatome defined a positive test), ability to raise legs ( $R$ ) for more than two to three seconds, and subjective feeling of warmth $(\mathrm{W})$ and heaviness $(\mathrm{H})$ in the lower limbs.

We calculated sensitivity (SN) and specificity (SP) for each sign at each minute, alone and in binary or triple combination. At four minutes we calculated the positive $(+)$ and negative ( - ) predictive value (PV) for each sign, alone and in combination with the others (assuming a $2 \%$ prevalence of unintentional intrathecal cannulation). ${ }^{2}$ When signs are used in combination the presence of either sign defines a positive test, while the absence of both defines a negative test. The PV (positive and negative) determines the statistical accuracy of positive and negative tests. Changes in BP from the baseline were compared at every minute interval using Student's $t$ test with a $P<0.05$ determining significance.

\section{Results}

Spinal analgesia was established later in all patients (i.e., all the catheters were located intrathecally). Analysis of demographic data (age, sex, height, and weight) confirmed comparability (Table 1). There were no changes in BP between the two groups (Table II). The SN and SP for each sign at each minute are shown in Table III. Table IV shows SN and SP of each sign alone and of the most relevant binary combinations at four minutes along with their - and + PV. At four minutes SN reached $100 \%$ for $R$ and $H$ (CI $78-100 \%$ ), while only $\mathrm{R}$ obtained a SP of $93 \%$ (CI 66-100\%). For R alone the -PV was $100 \%$ and the +PV 25\%. By using signs in combination of two or more, only $\mathrm{R}+\mathrm{H}$ reached $100 \%$ sensitivity and $71 \%$ specificity (-PV $100 \%$ and +PV 6\%). Finally the combination of $R+P$ obtained
TABLE I Age, height, and weight (mean \pm SD)

\begin{tabular}{lcc}
\hline & Study group & Control group \\
\hline Age $(\mathrm{yr})^{*}$ & $68 \pm 5$ & $68 \pm 6$ \\
Height $(\mathrm{cm})^{*}$ & $165 \pm 13$ & $170 \pm 9$ \\
Weight $(\mathrm{kg})^{*}$ & $77 \pm 15$ & $81 \pm 14$ \\
\hline
\end{tabular}

* $P>0.05$, study group versus control group.

TABLE II Systolic blood presure data in $\mathrm{mmHg}$ (mean $\pm \mathrm{SD}$ )

\begin{tabular}{lll}
\hline & Study group & Control group \\
\hline Baseline & $161 \pm 28$ & $156 \pm 18$ \\
1 Min & $156 \pm 26^{*}$ & $153 \pm 26$ \\
2 Min & $150 \pm 19^{*}$ & $150 \pm 24$ \\
3 Min & $143 \pm 20^{*}$ & $148 \pm 23$ \\
4 Min & $140 \pm 21^{*}$ & $150 \pm 22$ \\
5 Min & $139 \pm 23^{*}$ & $150 \pm 23$ \\
\hline
\end{tabular}

$* P>0.05$.

TABLE III Sensitivity and specificity of each sign at one minute intervals

\begin{tabular}{|c|c|c|c|c|c|}
\hline & \multicolumn{5}{|c|}{ Minute } \\
\hline & $I$ & 2 & 3 & 4 & 5 \\
\hline \multicolumn{6}{|l|}{ Sensitrity } \\
\hline Pin-prick & $47 \%$ & $80 \%$ & $93 \%$ & $93 \%$ & $93 \%$ \\
\hline Warmth & $80 \%$ & $93 \%$ & $100 \%$ & $93 \%$ & $93 \%$ \\
\hline Leg-raising & $40 \%$ & $66 \%$ & $86 \%$ & $100 \%$ & $100 \%$ \\
\hline Heaviness & $53 \%$ & $73 \%$ & $86 \%$ & $100 \%$ & $100 \%$ \\
\hline \multicolumn{6}{|l|}{ Specificity } \\
\hline Pin-prick & $100 \%$ & $100 \%$ & $85 \%$ & $85 \%$ & $85 \%$ \\
\hline Warmth & $85 \%$ & $71 \%$ & $85 \%$ & $71 \%$ & $71 \%$ \\
\hline Leg-raising & $100 \%$ & $100 \%$ & $100 \%$ & $93 \%$ & $93 \%$ \\
\hline Heaviness & $50 \%$ & $42 \%$ & $42 \%$ & $50 \%$ & $50 \%$ \\
\hline
\end{tabular}

TABLE IV Sensitivity (SN) and specificity (SP) of each sign alone and some in combination, along with their negative $(-)$ and positive $(+)$ predictive value $(\mathrm{PV})$ at four minutes

\begin{tabular}{lrlrr}
\hline & \multicolumn{1}{c}{$S N$} & $S P$ & $-P V$ & $+P V$ \\
\hline Pin-prick & $93 \%$ & $85 \%$ & $92 \%$ & $11 \%$ \\
Warmth & $93 \%$ & $71 \%$ & $91 \%$ & $6 \%$ \\
Leg-raising & $100 \%$ & $93 \%$ & $100 \%$ & $25 \%$ \\
Heaviness & $100 \%$ & $50 \%$ & $100 \%$ & $4 \%$ \\
Pin-prick and leg-raising & $97 \%$ & $89 \%$ & $96 \%$ & $15 \%$ \\
Heaviness and leg-raising & $100 \%$ & $71 \%$ & $100 \%$ & $6 \%$ \\
Pin-prick and heaviness & $96 \%$ & $67 \%$ & $95 \%$ & $5 \%$ \\
\hline
\end{tabular}

a SN of $97 \%$ and a SP of $89 \%$ with a -PV of $96 \%$ and $\mathrm{a}+\mathrm{PV}$ of $15 \%$. 


\section{Discussion}

Even though the use of adrenaline in an epidural test dose is only intended to identify intravascular injections, we decided to test the accuracy of an intrathecal test dose containing adrenaline as well as lidocaine to mimic the clinical situation.

We are aware that having a control group receiving the test dose via a catheter positioned in the epidural space would have mimicked the clinical situation more closely. However, that would have reduced our ability to maintain the study double-blinded. Also, signs and symptoms of epidural anaesthesia cannot be detected before five to six minutes. $'$

The incidence of unintentional intrathecal cannulation during the performance of a lumbar epidural block has been reported to be $2 \% .^{2}$ The intrathecal injection of epidural doses of local anaesthetic has been estimated to be $2 / 1000$ epidural anaesthetics. ${ }^{2}$ It may cause severe hypotension with respiratory and cardiac arrest. To identify epidural catheters located intrathecally, CSF aspiration via the catheter is attempted. After a negative aspiration, a TD-containing subarachnoid dose of local anaesthetic (usually lidocaine $45 \mathrm{mg}$ ) is injected via the same catheter. Therefore, recognition of signs of subarachnoid analgesia is essential to diagnose an unintended subarachnoid cannulation. In the clinical setting, assessment of function of the motor fibres (leg-raising and subjective feeling of heaviness), sensory fibres (response to pin-prick), and sympathetic fibres (leg warmth and hypotension) follows, in a few minutes, after the injection of a TD.

How soon can the diagnosis of unintentional subarachnoid injection of local anaesthetic be made? Our study shows that four minutes are needed to recognize signs of subarachnoid injection. A previous, unblinded, study has shown that only two minutes were needed in the obstetrical population. ${ }^{1}$ After three minutes or less the test has poor sensitivity, but allowing more time (five or six minutes) to elapse may make the diagnosis of intrathecal injection more difficult because of signs of epidural anaesthesia. More often, the epidural catheter is located correctly and, in the obstetrical population, signs of epidural anaesthesia may be recognized within five to six minutes. '

This study shows that assessment of motor function by leg-raising has the highest negative (100\%) and positive (25\%) PV. Therefore, leg-raising is a reliable sign to detect intrathecal cannulation. By using leg-raising all negative tests (patient able to raise legs after TD) will be true negatives (i.e., the catheter is not intrathecally located), practically eliminating the risk of unintentional intrathecal injection. A positive PV of $25 \%$ implies that, in the presence of a positive test (patient unable to raise legs after TD), $75 \%$ of the catheters may be erroneously thought to be intrathecally located. However, even though the frequency of positive tests is not known, it is likely to be very low (because we only had one false positive test out of 15 test doses, our study would suggest an overall incidence of positive tests between 4-8\%). Therefore replacing $75 \%$ of those catheters is clinically acceptable.

The data obtained in our study do not carry enough statistical power to determine if the use of pin-prick provides the same accuracy of leg-raising. Nevertheless, we conclude that pin-prick is not a better sign than legraising. Therefore the use of pin-prick as a single sign is unnecessary. The same conclusions can also be applied to the combination of pin-prick with any other sign.

The TD used in this study (lidocaine $45 \mathrm{mg}+$ adrenaline $15 \mathrm{mg}$ ) is isobaric when injected in the CSF at $36-37^{\circ} \mathrm{C} .{ }^{3}$ Therefore, subarachnoid distribution of our TD is not affected by the patient's position but depends on the site of injection.

In conclusion, we have found that: (a) four minutes are needed to detect signs of intrathecal injection of our TD; (b) leg-raising is a reliable sign of intrathecal injection; (c) the use of other signs will not improve the accuracy of our test and should be avoided.

\section{References}

1 Abraham RA, Harris AP, Maxwell LG, Kaplow S. The efficacy of $1.5 \%$ lidocaine with $7.5 \%$ dextrose and epinephrine as an epidural test dose for obstetrics. Anesthesiology 1986; 64: 116-9.

2 Dawkins CJM. An analysis of the complications of extradural and caudal block. Anaesthesia 1969; 24: 554-63.

3 Rosenberg $H$, Goldberger $N$. Density of local anesthetics: clinical implications. Reg Anesth 1978; 3: 3-5. 